\title{
Schizoanalysis and Ecosophy Scales of history and action
}

\section{Anne Querrien, Andrew Goffey}

In 1972, in Anti-Oedipus, Gilles Deleuze and Félix Guattari set out to replace psychoanalysis by schizoanalysis. When they did so, women's liberation ${ }^{1}$ and the affirmation of homosexual desire ${ }^{2}$ were beginning to magnetically attract political activities and reflection for some time. The love of women for other women catalysed a rebellion and a demand for single-sex political meetings, in which the problems of everyday life in their entirety were addressed, rather than discussions being limited to the vindication of a right to abortion and to contraception, as had previously frequently been the case. The male militants who were still dominant in May 1968 found themselves disorientated. This new subjective situation had nothing to do with the situation that had pertained in the beginnings of psychoanalysis, when young women from well-bred families, finding themselves hesitating between marriage and motherhood on the one hand, and paid literary or scientific work on the other, called like Virginia Woolf - for a "room of one's own" for the purposes of creative endeavour. The problem of desire - and this was something Deleuze and Guattari were tapping into - was no longer one of its channeling via castration, its repression through bourgeois decorum and manners, but its bolstering by ongoing social transformation, in the political emergence of affirmative minorities fleeing domination.

Schizoanalysis has both practical and theoretical origins, having been invented as much in the organisation of a collective milieu, in the framework of CERFI (the Centre for Institutional Studies, Research and Development), as in the clinical setting of the La Borde clinic and institutional psychotherapy. Above all it happened through the elaboration of an ensemble of concepts, which were to constitute so many tools for the concrete analysis of immediate dual or collective situations, and in analyses of a more prospective kind, the establishing of historical and political points of view on and for individual and collective action.

The operational core of schizoanalysis is formed by a handful of concepts: collective assemblage of enunciation; rhizome, faciality, refrain and cartography. With these, schizoanalysis aims not only at untangling individual difficulties in everyday life but equally at fomenting the collective adoption of attitudes able to generate development in the directions indicated by new social movements: ecology, the taking back of a creative relation to the earth destroyed by capitalism, with its belief that with its ever more frenzied deterritorialisation it could always produce more value. Schizoanalysis operates across and challenges the segmenting of life into the registers of the individual and the collective, the therapeutic and the political, the mental, social and natural. Moreoever, it also challenges a traditional separation of thinking and action, theory and practice, for as Guattari puts it "the very form of the division of labour between militancy, the analysis of the unconscious and intellectual activity should wither away."3

\footnotetext{
${ }^{1}$ Cathy Bernheim Perturbation, ma soeur (Paris: Seuil, 1983) and L'amour était presque parfait (Paris: Editions de Félin, 1991)

${ }^{2}$ Guy Hocquenghem Le désir homosexuel (Paris: Seuil, 1972)

${ }^{3}$ Félix Guattari Lines of Flight. For another world of possibilities (London: Bloomsbury, 2016) p.98
} 
After setting out some reminders about the way in which Guattari and Deleuze defined and sought to use these concepts, we will try to apply the main concepts ${ }^{4}$ of schizoanalysis to the significant optional matter which Guattari for his part discovered in the ecological movement, the militant movement that followed immediately after those of women's and homosexual liberation, and which took from these predecessors their respect for diversity and their attention to minoritarian options. Guattari not only took part in the ecological movement as a grassroots militant but also, in a much more original way, by proposing the elaboration of transversal connections between the different branches of its fragmented movement, with a paper - Le fil vert - and through his belonging to several of its different currents. Whilst the ecological movement in France had limited the scope of its reflections to technical problems, Guattari attempted to construct ecological problems as directly philosophical and political issues, as problems that were immediately ethical in nature because lacking any technical, or technocratic, solution. To do this he drew on the work of Hans Jonas $^{5}$, a student of Heidegger's, whose own position was nonetheless in many respects diametrically opposed to his own philosophical coordinates. Out of these reflections came a point of view that was both extremely acute and calming in its analyses, culminating in the publication of Chaosmosis, which appeared shortly before his death in 1992. So, we will try here to make the concepts of schizoanalysis function within the situations created by the ecological problematic and highlight the three dimensions of ecosophy, another of Guattari's later concepts. In ecosophy, environmental ecology, social ecology and mental ecology form three plateaux crisscrossed by movements on the different scales at which schizoanalysis was already playing out: the individual scale, which is already a molar scale in relation to the molecular scale at which different interpenetrating flows meet in both the human body and in ecological situations, which are at a different scale yet again to that of synaptic encounters inside the brain. Guattari's thinking as a whole is subtended by the hypothesis of a sort of holographic functioning that would give a similar image at every scale, a hypothesis which he seems to contradict with the inverse hypothesis of difference at every level, which ensures the change and renewal of images. It is this complexity - that of a system which is always moving, with multiple points of entry that we would like to make comprehensible to our reader, in order that $\mathrm{s} / \mathrm{he}$ might have at his or her disposal a polyvalent toolkit, a set of concepts that can be used to understand the situations in which he or she is involved.

\section{The collective assemblage of enunciation}

Involved since his adolescence in the political struggles engaged in by the French Communist Party in its cultural organisations and taking a particularly active role in the publication La Voie communiste, Guattari had many opportunities to observe how enunciation in a group is not the datum of an individual but is influenced by the collective that gives the individual an assertive strength. Likewise, in the psychiatric clinic, the psychoanalytic approach to patients is compromised by the difficulty patients have of speaking in a duel relation, with assuming the stance of the "personologically" individuated subject of enunciation. Speech is expressive in

\footnotetext{
${ }^{4}$ Our selection is largely pragmatic - there are of course other concepts that are important in the development and operative functioning of schizoanalysis. We do not claim to be making definitive statements here.

${ }^{5}$ Hans Jonas The Imperative of Responsibility: In Search of Ethics for the Technological Age (Chicago IL: University of Chicago Press, 1979)
} 
collective situations generated by diverse activities, in a context where the presence of carers is sufficient for such speech to be welcomed and something to be made of it. Expression also occurs through gestures, movements and objects introduced into conversations. Life in proximity to psychotic patients teaches us that one another's utterances in fact arise from collective arrangements, without which nothing would be uttered. On reflection we can see that the collective assemblages of enunciation of militants or citizens obey the same "laws," linking utterance to the dimension of transversality present in institutions of all kinds as well as in everyday life. In order to transform, say, what someone talks about incessantly so as to get beyond it, blocking them or cutting them off is pointless; what's needed is to introduce an object or some new kind of behaviour into their immediate environment, something they can apprehend, which will reconfigure their assemblage of enunciation and enable them to utter something new. This is how the prospect of passing one's driving test often opened up new outlooks for numerous people in analysis in the 1960s, and it is how Guattari learned to treat the psychiatric institution as a kind of modelling clay, offering "transferential grafts", potentialities for transformation and change, to its (im)patients.

Hence, as Guattari put it in The Anti-Oedipus Writings, schizoanalysis consists in inventing a language that replaces the (personological) subject of the statement/subject of the enunciation couplet, current in linguistics, which gives us subject understood as largely dominated by social conditioning, with a collective assemblage of enunciation, an articulation of desiring machines specific to the person in question and not (implicitly) contrasted with the social. In Anti-Oedipus Deleuze and Guattari ask: what are your desiring machines? If one sets out from the psychological subject and his or her social and economic determinants, for example, one will lose the dynamic proper to each of the strata that these determining factors form, and end up sticking them together in a static fashion, missing the movement that cuts across them. Envisaging enunciation as the subject in question's representation, this is a representation that can't help but be erroneous, because it inevitably lacks knowledge of all of the determinants that need to be taken into account. By contrast, if one constructs a diagram of the dynamic linking together the different forces in question, one can find a centre of gravity and of mobility into which the person can be invited to slip themselves so as to be better able to act in the situation that is bothering them. This analytic work can evidently be carried out on oneself, through an awareness of the singularity of one's position within a collective grouping, and doesn't necessarily require the expertise and privilege of an analyst against whom to counterpose oneself.

Hence the importance and necessity of looking for transversality, the coefficients of transversality, in the different social situations within which one moves. Such coefficients enable one to essay the construction of a diagram of the forces in relation to which one has to situate oneself and to address the way in which they animate the universe in which one is interested, keeping one's room for manoeuvre by taking up an oblique position in relation to these forces. Although Guattari had a lot of time for theory, in militant movements this more practical option means that the ideological differences by which people usually tear themselves to pieces are not given too much importance. What the transversal connections across a collective assemblage facilitate is an experimentation with a disjunctive synthesising of the different orientations towards action that are proposed within and across militant movements. Such a 
synthesis makes it possible to find a point at which heterogeneous forces (which under other circumstances might destroy each other) come into equilibrium - this is how he managed to keep going in the French Green movement. Fighting for an ecological transformation of society through government and the ballot box is not enough, given the extent to which the transformations that are needed depend on everybody's everyday conduct. The assemblages of enunciation within the ecological movement in France would, for Guattari, have to be formed transversally to the different currents that made it up. The relevant statement or utterance would be one that would enable a transversal unity to be achieved, that would have some prospect of application to the movement as a whole. But it's important to note that collective assemblages of enunciation can only appear in experiences and experiments on the ground that aim to make ecology itself live as a heterogeneous assemblage, mobilising different levels of power, producing new technologies, setting out images of the new life to come. As Cyril Dion and Melanie Laurent's film Demain (Tomorrow) and the now innumerable guerilla gardening initiatives show, such assemblages are not going to appear in the parliamentary, party political, arena.

Schizoanalysis set itself up following Guattari's theoretical undertaking with Deleuze to critique Freudian and Lacanian psychoanalysis, as a decidedly collective - and collectively singular - undertaking. Guattari practiced schizoanalysis by himself, in his consulting room, as well as with numerous militants, artists and intellectuals who were close to him in terms of their creative aims or political viewpoints. Biographical materials formed for them a kind of commons, which were worked on together and individually, in relation to specific time-scales and commitments. This sharing out of a social and collective concern, of a preoccupation with creation, made practice risky. A desire to work together that was left unsatisfied for example, might generate resentment that could be as violent as the transference that preceded it. The tendency of schizoanalysis was one of becoming a mutual practice that was generalised so as to allow for both a collective elucidation of the stakes of action - what should be done and the procedures to be followed in order to achieve collectively elaborated goals how should we do it. This was what the institutional organisation of the clinic at La Borde - with its complex play of group institutions and the "grille" - aimed to realise. It's also what the experiment with CERFI, in the late 1960s and early 1970s, was aiming at.

However, in CERFI's case, the precariousness of the public funding thanks to which it had developed (and the organisation's dependence on it), entailed the constitution of a mixed collective assemblage, which was in contradiction with what the funding system imposed, a kind of social-science-researcher-becoming. Other new collective assemblages were subsequently created on the basis of this professionalisation, assemblages which for their part were somewhat distanced from the experimenting with schizoanalytic concepts in which CERFI had engaged in its beginnings. Similarly, at La Borde, the tendency that Guattarian schizoanalysis had of exceeding the limits of the institution posed a problem for Jean Oury, who was the director of the clinic and had a responsibility for it vis à vis the authorities. The difficulties that Guattari himself encountered testify to the fact that revolutionary collective assemblages of enunciation, generating events, are always unstable and need to be protected as much as possible. The concept of the rhizome offers a way to explore a logic of relations within and through which collective assemblages of enunciation can 
be extended and flourish, and hence it forms the second concept in the schizoanalytic tool box that we want to consider.

\section{Rhizome}

The rhizome is a modality of relation which is opposed to the modality of relation that we most frequently encounter in the major sciences, in newspapers and in commentary of all sorts: the tree that starts out from an individual, the CEO of a business or the leader of some organisation, a person who forms a reference point for a genealogical tree and orders other people present within the field into a hierarchy. The rhizome, as Guattari (and Deleuze) tell us, connects any point whatsoever in a field with any other, through relations that aren't necessarily identical. Beings linked together by a rhizome are not necessarily of the same nature: a non-human, an animal, plant or object, can form part of a rhizome, just as they form part of a collective assemblage. The rhizome extends collective assemblages into a much vaster space, where the question of relation rather than enunciation dominates: what or who am I connected with, and do I - in fact - want to be connected?

Free association in psychoanalysis or schizoanalysis is one way of bringing to light a rhizome, of sharing with an analyst the knowledge of what or whom one is associated. ${ }^{6}$ Rhizomes are also fabricated through writing, minor writing à la Kafka in particular (who had always fascinated Guattari) which moves through the diary form, short stories, experimenting with different kinds of writing to give desiring machines and the difficulties in functioning with which they are connected, a capacity for movement to get beyond obstacles. Rhizomes are formed bit by bit, associating people and things as they encounter each other in a singular assemblage. A rhizome forms a multiplicity, a movement across an assemblage with an ever increasing number of dimensions, a production of lines that proliferate incessantly. Sooner or later, of course, a signifier, an invariant point, will take power, facilitating the attribution of the rhizome to, for example, an author, whom it will be taken as representing (as with the "oeuvre.") But at the moment that it takes off, at the moment that the heterogeneous materials of the rhizome are constituted (with their subterranean and invisible workings), the notion of the rhizome is a good tool with which to authorise the constitution of a heterogeneous material to work on, to get past the injunction to unify, to focus or fixate, and (thereby) abandon the seductions of the multiple.

Rhizomes make it possible to go a very long way in research, because they invite us to stretch out, to prolong and to relay the line or lines of flight that can be discovered in them. "Always follow the rhizome by rupture; lengthen, prolong and relay the line of flight; make it vary until you have produced the most abstract and tortuous of lines of $n$ dimensions and broken directions." ${ }^{, 7}$ Rhizomes are constructed gradually, without following any model or repeating a deep structure: they are fabricated, enacted, following the desire of each and everyone, each group, and change their form as connections accumulate and reconnect to one another. But rhizomes offer no assurance: there's no guarantee that a rhizome won't be transformed into a tree, taking a fixed form that dictates the relations between the points which, until then, it had

6 Max Dorra 'Pour une rêvolution des l'entendement' Chimères. Special issue on 'Les paradoxes du rêve’ No. 86 (Paris: ERES, 2015)

${ }^{7}$ Gilles Deleuze and Félix Guattari A Thousand Plateaus (Minnesota MN: Minnesota University Press, 1987) p.11 
connected. If this happens, the rhizome is dead or dying, that desire can do nothing but replicate well-worn paths and conform to a normal - and normalised - structure, which channels the multiplicity of movement from point to point. And yet rhizomes can nonetheless be remobilised - albeit at the cost of some difficulties - as productive outgrowths on dead trees. This is the kind of work that schizoanalysis tackles.

The multiple rhizome which each of us constitutes, through our writings, paintings, myriad creations, which weds the movement of desire in its connections with everything that surrounds us, Deleuze and Guattari tell us, has neither beginning nor end but rather "it grows and overflows from the middle/milieu." 8 This is a piece of very practical advice that is often repeated in Deleuze and Guattari's common work: take things by the middle, in their milieu, don't try to make them depend on origins. Things quickly escape their origins, and the search for origins doesn't tell us all that much about the actual factors through which they are currently being determined. It is in the middle, in a milieu, that things happen, that desire flourishes, growing in all sorts of directions via the lines of the rhizome. Do a drawing of your rhizome, write it, put it together gradually, as the movements of your desire evolve, and you will find these different movements gaining strength. This is the contrary of what happens when such movements are traced back to the fiction of a common origin, which forces you to put to one side everything that you can't link back in that way. There will be more to your desire as you become a free, shifting, mobile subject, even if you move in very minimal ways. Making a rhizome is the basic tool for doing schizoanalysis.

\section{Faciality}

The expression of affect, the displacements brought about by desire, bud and flower on the face, but they can only be detected here because the face has been the object of a long-term modelling over hundreds and hundreds of years that has endowed it with axes, coordinates and transformed it into a flat surface for inscription. Judaeo-Christian history has imposed the face of Jesus Christ as the ultimate reference point for this placid, platitudinous common-place, a point of fusion between suffering and jouissance. As an object for the relentless work of painters and sculptors over twenty centuries, expression and its potentialities, as they come to light in the face, have been confiscated by representation and its possibilities, in a process by which the body is made submissive to the mind and accorded a representational signification. For Guattari in The Machinic Unconscious ${ }^{9}$ faciality forms the coordinates of the face that intervene so as to define what is and what isn't licit, what is and isn't similar, what does and doesn't resemble, so as to reterritorialise what escapes when rhizomes are produced. The face - a bit like space itself - is referred here to a planar geometry, one that is formed by the eyes, the forehead and the nose, "which gathers together, formalises, neutralises and crushes the specific traits of the other semiotic components" 10 that attract the gaze, to which it opposes its immobility, relative to the mobility of other elements of the body. The planar geometry of the face is what you look at in a portrait and it's what you see when looking at someone you are listening or talking to, guiding your responses. The movement of attraction through which the faciality machine operates transforms the eyes of the other into veritable black holes, into tensors for the destruction of alterity. Any movement beyond this tension can

\footnotetext{
${ }^{8}$ ibid p.21 (translation modified)

${ }^{9}$ Cf Anne Sauvagnargues Artmachines (Edinburgh: Edinburgh University Press, 2015) pp.218-231. 10 Félix Guattari L'inconscient machinique. Essais de schizo-analyse (Paris: Editions Recherches, 1979) p.79
} 
only risk social exclusion. As Guattari often emphasises, there is an "optional matter" as regards one's conduct in this field of faciality: either one submits to dominant capitalist facialitarian forms, integrating oneself with the forces of repression of desire - both for oneself and for others - or one develops singular faciality traits, picking up the thread of the rhizome again, by avoiding black holes and allowing oneself to be carried off by the machinic connections of lines of desire. Schizoanalysis cannot in and of itself make this choice on behalf of the analysand - but it can help the analysand to clarify the terms on which such a choice is made. Thinking faciality allows the analysand to follow the ways in which it is effectuated in the concrete faces that surround him or her, without having to pass via forms of expression - in language - that entail even more subjection to convention and crushing self-evidence than those of the face. Teasing out the face and the limits of its codification of desire in turn facilitates an apprenticeship to the signs by which we are surrounded in everyday life, the myriad blinking, winking eyes, black holes and - hopefully - a-signifying faciality traits that look out at us from screens, walls, billboards, surfaces of all kinds.

But faciality does not start and end with the human face. It extends to the face of the earth, to landscapes that are only fixed and "natural" for those whose profession it is to obey their destiny, even whilst desire is constantly fabricating mobile images, dynamic and fugitive differences. All civilisations have endeavoured to produce rules for the representation of the landscape, and as with the cases of the face and the portrait, they have played on the duplicitous posture of freedom and creation for the clerics and subjugation for the population at large, who are subjected to obligatory users guides and models of vision. The invention of the perspective and of chiaroscuro, for example, led to the landscape art of classical times. Chinese fen shui equally drives the art of the painter and the gaze of the spectator. And within modernity it is the phoographic apparatus which frames the way in which the landscape, or the face in the portrait must be seen. One might equally refer to the demand made by Jesuit priests on the faithful - to compose in their mind's eye a landscape for the life of Christ in order to prepare them to receive God. If this resulted in the Jesuits finally being obliged to catalogue such landscapes in picture catechisms, this was because the faithful clearly struggled to do their spiritual exercises correctly. The contemporary landscape, of course, is marked by war, desolation and waste: from coal tar sands and despoliated rain forests through refuse dumps and industrial wastelands. As Guattari puts it: "we are now in the presence of a double movement, that of:

- the constitution of a face-landscape which is deterritorialised from the inside and focuses on a microscopic black hole which is at one and the same time a vanishing point and central point, a point of arborescence and of closure, the translation of which generates the illusion of a homogeneous world of signification; and

- the setting up of facialitarian syntaxes that generate the illusion that the universe of abstract machines also arises from centralising structures, from a monosubjectivism, a monotheism, which is correlative to the degeneration and decline of the polycentrism of animal and animist cosmologies." 11

This faciality-landscaping ${ }^{12}$ tends to dissolve the territorial limits of traditional societies even whilst - through its central, guilt-inducing eye, on which all the

11 Guattari L'inconscient machinique op. cit. p.92

12 We have preferred here to render the neologism "visagéité-paysagéité" as "faciality-landscaping" so as to avoid the ugliness of "faciality-landscapity." 
coordinates of representation are based - maintaining its hold on the social in its entirety. Whether it is in the service of domination or forms part of a militant and artistic search for deterritorialisation, the media work at modifying faciality traits, so as to pull them back in to the centre or, on the contrary, to distance themselves. The latter, centrifugal, tendency is of course all the more difficult accede to, given the multiplicity of directions to explore. With its claims to universality, it is thus attraction by the centralising force of faciality that makes itself felt the most, particularly given that it founds the individuation of enunciation on the tangent between the libido and capital, in the feeling of emptiness which is at the origin of the existential anxiety characteristic of capitalism in its declining years. It's no longer the case that modern faciality traits are articulated with local components, as in deterritorialised collective assemblages: faciality traits have become abstract, binary characteristics that classify individuals according to typifiable distances from a statistical norm. Guattari gives a systematic cast to the damaging effects of this oppressive capitalist faciality, which smoothes out the world in one direction only, that of abolition in the black hole of the superego. "Capitalist faciality teaches us to not see, to abstract out from the richness of things, to adopt a limited point of view, from this side of which identification becomes impossible....At the end of the day it is this faciality that maskes the subjugating functions of the dominant semiologies by presenting its operations as being grounded on invariable logical procedures rather than on concrete apparatuses of power."13

But at the same time, Guattari also insists on the other possible option, the option that schizoanalysis will seek to develop, through the marking out of lines of flight and the production of a machinic rhizome susceptible of carrying faciality traits away from the tolerable deviations from superegoic redundancy. The invention of new machines and of practices with them, as in the case of computers, is what will allow for the proliferation of experiments with new faciality traits or new landscaping traits. However - and here a little schizoanalytic pessimism is necessary - semiotic treatment through information technology is still very poorly adapted to the analysis of deterritorialised processes, because it too rests on the binarity of the signifier, predisposing it to the poor treatment of inclusive disjunctions, and to a preference for trees. Let's not forget here how much structuralist thinkers such as Jakobson, LéviStrauss and Lacan were attracted to cybernetico-informatic concepts.

Faciality and its landscapes form very particular territories of expression, and rather than simply criticising them or trying to ground them in universals, schizoanalysis seeks out and follows carefully any of the artful, artificial attempts at modifying them that might enable the desiring capacities of machines to develop.

The transformation of the face of the earth through the landscaping traits that sustain binary machines, is the principal focus of attention of ecology and so it offers one way of branching across into Guattari's later thinking. It is through the transformations of the landscape that one starts to realise to what extent the entire surface of the earth has been littered with the harmful toxins of a demented system of proprietary production, or just how much the capacities for renewal of the earth have been compromised. Ecology seeks to intervene on the surface of the earth through new practices that are more respectful of natural cycles. Ecosophy develops three levels or dimensions of 
apprehension of relations to the earth. Mental ecology works on rebuilding the link of each and everyone to the earth, wrecked as it is by the extreme deterritorialisation of capitalism gone astray by a concentrating of all attention on private property or by State-led identitarian fixation on what region someone comes from or belongs to. Social ecology develops new relations of production between humans, or between humans and non-humans, and works towards a situation in which respect for the latter, for the landscape, the quality of the earth, provides the opportunity for a transformation of relations of production, in a more gentle direction, towards greater respect amongst humans. Environmental ecology provides the knowledges that will allow for these new relations to be explored and developed. The concrete contents of these ecologies will differ according to place, and the landscape traits in play will thus also be just as diverse as the new assemblages of jouissance and territoriality put into play by ecoscophic praxis. Guattari nonetheless envisaged a fundamental shift in his ecosophical apprehension of the transformation of the face of the earth, which was that the assemblages of the three ecologies would be decentralised, unlike the centralisation that capitalist faces and landscapes aimed at, and which technocratic tendencies in traditional ecological thinking did little to question. Everything is up for re-invention and re-assembling with the breaking up of capitalist faciality.

\section{Refrains}

Faciality and its landscapes are visions, powerful images capable of animating collective behaviour and of triggering the seduction of individuals. In the domain of sound, the role of capitalist encoding and of the shifters of singularisation are assumed by refrains. For both, Guattari provides an exploratory formulation in The Machinic Unconscious, which he reprises - repeating with deterritorialising variation - with Deleuze in a quasi-pedagogic fashion in A Thousand Plateaus. However, refrains have for the most part been studied much more as signalling the emergence of a particular territory, as the product of an action that aims at making this territory emerge, rather than from the point of view of their role in capitalist encoding. Numerous musicians, for example, have taken up the concept of the refrain as an inspiration for the way they work the relations between repetition and creation, as in Pascale Criton's 1995 composition "La ritournelle et le galop" in homage to Deleuze. Or in the work of the Brazilian musician and professor of musical theory, Silvio Ferraz, for whom the refrain is a machine for the production of differences, for connecting lines of flight, codes, milieu and rhythms. For both of these musicians it is a matter of assembling a plurality of components and of constituting a territory in which such components enter into modulation and then leave, freeing up autonomous microfragments which will constitute new knots of assemblages, and so on. Every model of composition is like the entrance point into a territory whose rules have not yet become stratified. The deterritorialising refrain allows for the passage from one milieu to another. A new persona-component is borne from the modulation between the components of associated milieus. Heterogeneous sounds combine in a "new refrain into which unforeseen modulations enter, in a free play of connections to bring about other refrains and unforeseen modulations." 14 The musicologist Maël Guesdon has emphasised the importance of Guattari's preoccupation, since his very earliest writings, with the material and psychic effects of repetition on subjectivity. Right from the outset he was seeking to construct what Guesdon calls a sensory ecology of expressive speeds (allures expressives), questioning how the living appropriate the

14 Silvio Ferraz 'La formule de la ritournelle' in Pascale Criton and Jean March Chouvel (eds.) Gilles Deleuze, La pensée-musique (Paris, Centre de documentation de la musique contemporaine, 2015) 
forms that surround them and compose the milieus in which they live, so as to make of them territories inhabitable by all. Guattari equally looked to history to discover how groups of humans constituted sounds as signals to affirm their identity, to group their members together and to defend themselves from their enemies. He looked to biology for similar examples of the use of signalling by sound in the relations within or between groups of animals. This was a question that had already been explored by Eibl Eibesfeldt and Paul Géroudet in relation to birds: from a common base their songs differ slightly so as to signal circumstances to be indicated to partners or strangers. Like birds and animals more generally, in the everyday humans express a constant stream of refrains, which detach themselves on the margin of capacities to knot together new relations, freedoms that are subject to choices oriented towards opennes, and therefore also to micropolitical conflicts. Inversely, an event, an encounter, can only be effective if it composes itself with the characteristic refrain of the individual or group concerned. The refrain plays the role of a component of passage between the world before and the world after, and one notes here once more that in Guattarian vocabulary, this doesn't occur through words or signification so much as through a tonality, an air, an ambience which speaks volumes about the sense of the operation.

In A Thousand Plateaus, the way that Deleuze and Guattari reprise the latter's intutions about refrains articulates a question about artistic creation, whereas in The Machinic Unconscious it was only a question of biology and sociology, of the modulation of human and animal sounds. The plateau 'Of The Refrain' opens with a reproduction of Paul Klee's Twitter Machine (which students of Deleuze have a habit of sending to each other to show their expressive, desiring capacities - regrettably, with the development of social media, twittering has become much more attenuated as an image of desire). The plateau defines the refrain in the same way as does Silvio Ferraz: movement from chaos to the territorial assemblage, organisation of the territorial assemblage, leaving the territorial assemblage for other assemblages, the formation of a process producing life. Deleuze and Guattari set out here a veritable user's guide for the concepts of territory, milieu and rhythm: "there is a territory when rhythm has expressiveness. What defines the territory is the emergence of matters of expression (qualities). Take the example of colour in birds or fish: colour is a membrane state associated with interior hormonal states, but it remains functional and transitory as long as it is tied to a type of action (sexuality, aggressiveness, flight). It becomes expressive, on the other hand, when it acquires a temporal constancy and a spatial range that make it a territorial, or rather territorialising, mark: a signature." 15 And they continue by affirming that it is the artist who is the first human to set out the limit or make the mark that defines a territory. Romulus and Remus - and all the other founders of cities - would doubtless disagree with them, united as they are in the culpabilising belief that the foundation of a city necessitates, in the first place, a sacrifice. Deleuze and Guattari apply themselves to describing the nomadic space in which the signature has value as a temporary possession, in which in the long term, property has no meaning, something of a model, then, in our epoch, in search of the common. The refrain expresses this temporary territory: "matters of expression enter shifting relations with one another that 'express' the relation of the territory they draw to the interior milieu of impulses and exterior milieu of circumstances."16

15 Gilles Deleuze and Félix Guattari A Thousand Plateaus (Minnesota: Minnesota University Press, 1987) p. 315

16 ibid p.317 
The rest of the plateau makes these expressive refrains into faces or rhythmic personae, counterpoints to the melodic or harmonic faces and landscapes produced by the fashioning of transcendents. This reprise testifies to the emancipatory character of the refrain signalled by Ferraz. The analysis of the refrain is founded on that of the territory, and territories are far from being containers or belongings. As we have seen in the case when Guattari writes about this alone, the territory is a component of passage, a condition for the formation of a creative process.

However, Deleuze and Guattari together add to this a concern for "consistency," making the refrain of central importance to a question that had concerned Guattari since the mid-1960s. ${ }^{17}$ To make a set of heterogeneous elements hold together, rhythm synchronisers are needed, just as machines are needed to make an assemblage hold together. Indeed, this is a hypothesis that, in different ways, individually or together, Deleuze and Guattari everywhere maintained: it is the cutting edges of deterritorialisation, the most deterritorialised element of the assemblage which, in carrying off the other elements of the assemblage, makes the assemblage hold together. Deterritorialised, heterogeneous consistence always has primacy over reterritorialised, homogenised, substance. Except, as they themselves point out, the consistency of the assemblage comes up against the stratification of the milieus. ${ }^{18} \mathrm{~A}$ fascinating analysis of the oeuvre of Paul Klee and of the comparative merits of painting and music in leading us into the cosmos follows their discussion of consistency, and it stresses the ways in which these two arts achieve a molecularisation of their respective matters of expression, to the point of facilitating complete deterritorialisation. We then come back again to the refrain - to its sticky, territorial attachment on its fascist side, and on the other, to the way in which its inventiveness gets madder and madder (to the extent that machines capable of accompanying it can develop).

"So just what is a refrain? Glass harmonica: the refrain is a prism, a crystal of space-time. It acts upon that which surrounds it, sound or light, extracting from it various vibrations, or decompositions, projections or transformations. The refrain also has a catalytic function: not only to increase the speed of the exchanges and reactions in that which surrounds it, but also to assure indirect interactions between elements devoid of so-called natural affinity, and thereby to form organised masses...It is of the nature of the refrain to become concentrated by elimination in a very short moment, as though moving from the extremes to a centre, or on the contrary, to develop by additions, moving from a centre to the extremes, and also to travel these routes in both directions." 19

From the middle of the 1980s onwards, Guattari moved closer to the ecological movement, a relative newcomer to the political scene. The ecologists were - and still are - radically opposed to any of the kind of major works that are likely to accelerate the flows of humans and commodities, the growing speed of which they consider to

\footnotetext{
17 The question of consistency becomes a concern in the later essays of his Psychoanalysis and Transversality as well as in his Anti-Oedipus Writings. The link between the former and the refrain have been commented on extensively by Gusdon

18 Deleuze and Guattari A Thousand Plateaus op. cit. p. 336

19 ibid p.348-9 (translation slightly modified)
} 
be the principal cause of the ruining of the planet and the potential cause of new armed conflicts in the struggle for access to raw materials. Guattari seems, little by little, to have felt the need to abandon an affirmation of the benefits of the infinite processuality that forms the basis of the transformation of the refrain into a crystal of time, a crystal that is perhaps capable of operating at a molecular level without any human intervention, in favour instead of a new configuring of the world to be defined. Although his appraisal of refrains will undergo further developments (in Chaosmosis), it is his sense that the ecological problem cannot be reduced to the harmful effects of a way of life and an economy which would only need changing quantitatively - and thus in a reactionary manner in relation to the social practices in effect, that starts to matter. What is needed is to succeed in following experiments with new ways of living that are being tried out by people most sensitive to these kinds of question and, in particular, to understand how they articulate a transformation of the interests and attention of militant subjectivity, with a modification of social relations in the workplace, in the ways in which public spaces are occupied, in practices of aid and of solidarity, with the recomposition of geopolitical relations. It is not a matter of falling back on convivial little territories and humming little ecological ditties in familial relations but of opening up a welcome to migrants, of participating in struggles to end the dependence of the economy on oil, the end of exploitation in the global South. To see such a programme through, a personal and collective development is needed for everyone, for which Guattari's Schizoanalytic Cartographies offers some means for orienting oneself.

\section{Schizoanalytic Cartographies}

Throughout his life as a researcher, whenever discussing rhizomes, faces, landscape, or even the viewing the diversity of refrains in space, Guattari evoked the cartographies of desire. In his critical combat with the institutions of psychoanalysis, his ambition was to give everyone the means to orient themselves in the trajectories of their lives, to enable others to get a vision of this to facilitate a collective apprenticeship to the transformation of existing social coordinates. Guattari's cartographies form part of his challenge to the presumptive authority of "psy" expertise. Criss-crossing the history of the world, A Thousand Plateaus situates concepts in particular social, linguistic and political configurations but only admits this singularisation of the trajectories of desire at the risk of their reductive analogisation, even their falling back on historical configurations that are simply not adequate to bear them. In this regard, what Guattari, continuing to think schizoanalytically, felt the need for was method of visualisation, one that would allow for a radical analysis of the equation that is proper to a given individual as well as the grasping of the history of the world in all its dimensions.

For Lacan, of course, grasping the trajectories of desire entailed the Borromean schematisation of the real, the imaginary and the symbolic, a tripartite division and articulation that has the advantage of being able to cope with every situation, in a manner that is universalising (a requisite for the basic coordinates of a cartography) even as it posits the impossibility of universalising formalism. Its disadvantage, however, is that it doesn't really offer any way of making reference to the world as it is made within human history, other than as it can be apprehended through "batteries of signifiers." Guattari's Schizoanalytic Cartographies by contrast thus has four dimensions, enabling it to incorporate a reference to time, to the accumulation of 
experience within human history, and to the world and its movements independent of the human. ${ }^{20}$

Always grasped through their articulation within the dynamic cycle of assemblages, the four dimensions (marked recurrently using the FTU $\Phi$ abbreviation) in relation to which Guattari thus situates the history of the world and individual history are the following:

1. The dimension of material flows $(\mathrm{F})$, which in many respects approximates Lacan's real, but with Guattari's heavy insistence on the fact that matter at the molecular level is made of particles. The most numerous of such particles electrons - are in motion, a motion that can and does produce unforeseen encounters, events, out of which new configurations of flows can be formed, such that there is nothing definitive about any flow at all. At every possible scale, it is the fluid multiplicity of matter - and not the reassuring figure of nature - which through its unforeseen twists and turns has the capacity to modify our environment in a manner that is, crucially, independent both of our will and our apprehension.

2. The existential territories $(\mathrm{T})$ which form the milieus in which humans and animals, even plants (according to the most recent of research) evolve, in which the living being transforms its environment through its actions, conserving it for itself, whilst destroying it for other species. In short, existential territories are also to be understood in terms of irreversible transformations which aim at permanence.

3. Incorporeal universes $(U)$, which are formed through the transformation of existential territories and their impetus to form operators of conservation and transformation, through the abstraction of qualities that are present in those territories and the actions that lead to them. It is on the basis of existential territories that surplus values of code are constructed, driven by the deterritorialising and deterritorialised flows that define common tools, disciplines, theories, musics. These surplus values of code are apt to push the deterritorialisation of existential territories further, extending the possibilities for opening up inherent in incorporeal universes.

4. The machinic phylum $(\Phi)$ to which the territorialisation of flows gives birth throughout human history, via their intersection with the operations that the conceptualisation of incorporeal universes, and the production of more or less powerful collective assemblages of enunciation allow. The philosopher Gilbert Simondon has outlined the principle of this machinic phylum and its production, most notably through the hybridisation of disciplinary fields that previously developed separately from one another. Unlike Simondon though, Deleuze and Guattari together, and Guattari by himself (in both Schizoanalytic Cartographies and Chaosmosis) offer a much more extensive definition of the machine than the more obviously classical one offered by Simondon. Any cutting into a flow forms a machine, as far as they are concerned: the baby's mouth when it is drinking breastmilk, for example. In this respect and following this more extensive definition, the machinic phylum is both historical, for everyone, and specific, depending on how the flows in question are cut (into) in each case. Where someone is situated cartographically will be defined by searching for the flows

${ }^{20}$ The formalisations of expression and content, which had played a crucial role in both his own work and that with Deleuze, are to be understood here as particular stases of the deterritorialised semiotic energies that the four dimensions articulate. 
that animate them, by the flows one cuts into as a way to fuel - rather than fetter one's own dynamics.

In very practical terms, knowing about the flows $(\mathrm{F})$ one is animated by makes it possible to deduce what existential territory $(\mathrm{T})$ one belongs to and how one can intervene in and modify it. But with what political theories or ideologies? What practices of abstraction? In relation to what disciplinary references? (U) And perhaps, even, through the invention of what new machines $(\Phi)$ ? And how, through further, deterritorialising cycles of the assemblages through which these four "functives" are articulated, can one extend and prolong the potentialities thereby made available... Every action, every project, in fact requires the invention - the instituting - of a specific apparatus, one that is adapted to one's projects, conditions, to the collective assemblage that will put it to work. Likewise, everyone should, with the help of the diagrammatic tools of schizoanalysis, be able to detect the principal flows that force the movement of his or her situation, the existential territory with/in which one operates, what additional universes of reference will be needed to act and which incorporeal domains to turn to, so as to articulate flows and knowledges in a new machinic production.

A more intent and careful consideration of Guattari's revised proposals for machinic analysis make some of the limitations of recent protests more evident: proposing the occupation of public spaces as their principal political means, they seem happy simply to broaden out or relink existential territories, without considering how to transform the incorporeal universes that serve as their reference points or how to produce the new machinic operators that are indispensible for transforming the global situation. As such they are at risk of falling back onto identitarian and/or compensatory demands and of missing the broader ecological dimensions of the impasses of contemporary capitalism. The diagrammatic mapping processes that Guattari develops require a more radical transformation of our relations to the earth.

The relatively complex language that Guattari uses to set out his analysis registers this difficulty of transforming a schizoanalytic cartography into an operative short-term cartography. It seems that in the ecological domain, the possibility of existential territories evolving in the direction of a veritable experimentation with new territorial inscriptions is being affirmed with increasing insistence, to the extent that traditional configurations of environmental exploitation have turned out to be dangerous impasses. "Cheap nature" as some are calling the ultra-exploitative capitalist regime of extraction, is coming to an end. But strangely, in his ecosophy, Guattari adopts a tripartite representation, even though - as he had very clearly explained with Deleuze (in Anti-Oedipus) - such a representation would only ever result in the dimensions of time and history being evacuated. If we try to hybridise schizoanalytic cartographies with ecosophy, we might hypothesise that the dimension of flows, of the real which sustains the myriad transformations of energy around which the Cartographies are organised, forms the environmental ecology addressed to the transformation of the planet at the very different scales of elements and territories. Social ecology would be dealt with by existential territories, in the sphere of what Lacan calls the imaginary, social representations of life in common, and endeavours to transform them as a function of new principles, such as those of equality - of gender or of humans more broadly, or, in a more Deleuzoguattarian manner, animal- vegetable- or imperceptible becomings. Mental ecology, for its part, would be produced through the incorporation 
into such becomings of new scientific knowledges, and through the incorporation into everyday awareness of new ethical reflections. Guattari's psychiatric practice in turn rendered him sensitive to a dimension of this ecology that few specialists think about, that of existential anguish faced with the negative promises of the future. The sentiment of the "end of the world" that other psychiatrists (particularly Tosquelles) had picked up on in relation to psychosis here acquires a peculiarly world-historical dimension. However, the possible transposition of the four-headed thinking of cartographic thinking into ecosophy leaves some tasks still to be worked through. The machinic phylum, the material, rather than imaginary, production of new modes of life, the processes of putting becomings to work, remains to be integrated into ecosophic reflection, in an ecology of machines or an ecology of images, such as that proposed by Anne Sauvagnargues, ${ }^{21}$ without which the ongoing production of subjectivity that both schizoanalysis and ecosophic praxis demand risk missing a vital resource.

\section{Chaosmosis}

Guattari's Chaosmosis ${ }^{22}$ registers a state of total disillusionment in relation to the methods that have been employed hitherto for the conduct both of individual subjectivity and for the relations between social groups or human societies. Chaosmosis is the registering of a state of confusion and of the weakening of the markers necessary in the face of the current state of the world, an obligatory passage for whoever wants to reshuffle cards and create. Chaosmosis is not the old revolutionary tabula rasa but registers a breakdown of previous relations which pushes towards a new articulation of resources, across all dimensions of existence. Planetary problems linked to climate change and the dwindling of raw materials will only be resolved through violence and bloodshed, as we are seeing in the multiplication of wars today, unless social relations, international relations, but also the mental resources that are employed to tackle these problems, both individually and collectively, are not profoundly transformed. Whilst the creativity of desire in $A$ Thousand Plateaus generated infinite openings, Guattari's ecological research, in particular following his reading of Hans Jonas, had led him to rethink his perception of the development of the world, in a more intensive, microscopic direction, that of an infinity tending towards the infinitely small. Becoming imperceptible, which had already been evoked as the "destiny" of all becomings in $A$ Thousand Plateaus ${ }^{23}$, entails an ethical positioning, the search for a transformation of the world on the basis of where one finds oneself in it: a "micropolitics" 24 of interactions that is animated by a search for the common. Communism in this sense ceases to be what it was in Guattari's youth - a space to be conquered, gun in hand - but something to be created at every moment, wherever one might happen to be, with whatever means one has at one's disposal. Everywhere that subjectivity is liberated, freed up from what conditions it, what keeps it on a leash and obliges it to participate in maintaining domination, it can become invested in tangible projects that can offer a means of orientation for this molecular revolution. Chaosmotic in its modes of propagation, this revolution from below will not be victorious straightaway, but it will disturb the

\footnotetext{
${ }^{21}$ In her Artmachines op. cit.

${ }^{22}$ Félix Guattari Chaosmosis (Sydney: Power Institute, 2005)

${ }^{23}$ Deleuze and Guattari A Thousand Plateaus op. cit. p.

${ }^{24}$ Suely Rolnik and Félix Guattari Molecular Revolution in Brazil (New York and Los Angeles: Semiotext(e), 2008)
} 
powers that be sufficiently to make them produce, somewhat reluctantly no doubt, fissures and cracks into which the desire for change that already exists will rush.

Perhaps the tools described above will not be sufficient to enlarge these fissures and cracks and develop ecosophical spaces. But they do indicate the direction in which to look for the new modes of existence on the way to being created. Schizoanalysis and ecosophy conjoin their efforts in detecting the emergent, and in sorting through all the propositions that strengthen the living creature, the animal, the human and the cosmic. By building bridges, transversal (disciplinary, professional, militant) connections between these efforts, schizoanalysis and ecosophy form together forces in a position to undermine the mental, social or environmental rocks that hinder the flourishing of desire and its transformative potentialities. Whether this is at the individual scale of an analysis tackling the relationship with others and the world, or at the collective scale of an organisation that sets out to be a force for life and transformation, or, indeed, at the planetary scale, indispensable to the analysis of changes underway, schizoanalysis and ecosophy come together to arm us in our desire for a "new softness", as Guattari put it in Chaosmosis. 